\title{
Early Mathematical Performance in Finnish Kindergarten and Grade One
}

\author{
Riikka Mononen \\ Department of Teacher Education, Special Education, University of Helsinki, Finland • \\ riikka.m.mononen@helsinki.fi \\ Pirjo Aunio \\ Department of Teacher Education, Special Education, University of Helsinki, Finland
}

\begin{abstract}
The present study assessed Finnish kindergarten ( $\mathrm{N}=177$, Mage $=76.4$ months, $\mathrm{SD}=3.7$ months) and grade one ( $\mathrm{N}=178, \mathrm{Mage}=87.2$ months, $\mathrm{SD}=3.7$ months) children's mathematical skills in the beginning of the school year. The mathematical skills were assessed once using researcher-developed paper-pencil tests. The variance analysis (ANOVA) was used to study the effects of age and gender on performance level. Boys and girls performed similarly in both samples, but age effects were found in the kindergarten and first grade; older children performed higher than younger ones. The older children may have had more opportunities to practise and get acquainted with mathematical issues, as the age difference between the youngest and the oldest child in the classroom can be up to one year. Children performing at or below the 25th percentile in both samples showed significantly weaker performance in several mathematical skills (i.e., number word sequences, enumeration, and addition and subtraction), compared to other performance groups. On the other hand, many children already understood in the beginning of the school year much of what is considered in mathematics curriculum and materials in their forthcoming school year in the kindergarten or the first grade.
\end{abstract}

Keywords: assessment, first grade mathematics, gender, kindergarten mathematics, lowperforming children

\section{Introduction}

Children have large individual differences in their early mathematical skills (Aunio, Hautamäki, Sajaniemi, \& Van Luit, 2009; J ordan, Kaplan, Ramineni, \& Locuniak, 2009), and those children starting with weak skills seem to perform more poorly than their peers along the school years (J ordan, Kaplan, Locuniak, \& Ramineni, 2007; Morgan, Farkas, \& $\mathrm{Wu}, 2009)$. Supplemental instruction, hence pedagogical interventions, has been shown to be effective in supporting the development of the important prerequisite mathematical skills in low-performing children (Aunio, Hautamäki, \&Van Luit, 2005; Bryant et al., 2008; Räsänen, Salminen, Wilson, Aunio, \& Dehaene, 2009). With additional support, some of the children have been able to bridge the gap to their typically performing peers (Bryant et al., 2011; Klein, Starkey, Clements, Sarama, \& Iyer, 2008). In the present study we were interested in how the performance of kindergarten and first grade children in mathematical skills varied, if gender or age would affect the performance, and which mathematical skills 
were especially difficult for low-performing children. The focus was in key areas of early mathematics, such as number word sequence, enumeration, as well as basic addition and subtraction skills, which are proven to have good predictive power for later mathematics performance.

\subsection{Early mathematical skills}

There are several mathematical skills developing in children before formal mathematics instruction begins at school (Sarama \&Clements, 2009). At the core of development is early numeracy, including the ability to operate with number word sequences and enumerate, combined with mathematical-logical thinking skills (Sarama \& Clements, 2009; Krajewski \& Schneider, 2009). In addition, early numeracy skills will elaborate in the child's development to basic addition and subtraction skills. Longitudinal studies from kindergarten up to fifth grade report that the early numeracy performance (measured as using research-based mathematical assessment batteries) in the beginning of the school career is a good predictor of the mathematical performance later on at school (Aubrey, Dahl, \& Godfrey, 2006; Aunola, Leskinen, \& Nurmi, 2006; J ordan, Glutting, \& Ramineni, 2010; Kurdek \& Sinclair, 2001; Lachance \& Mazzocco, 2006). Several sub-skills have been found to have predictive power for later math performance, such as counting (Aubrey et al., 2006; Krajewski \& Schneider, 2009), basic arithmetic (Aunola, Leskinen, Lerkkanen, \& Nurmi, 2004), number knowledge, nonverbal calculation, story problems and number combinations (J ordan et al., 2007), number line and magnitude comparison (LeFevre et al., 2006), number reading (Passolunghi, Vercelloni, \& Schadee, 2007), and numeracy related logical abilities (e.g., seriation, classification) (Aunio \& Niemivirta, 2010; Desoete, Stock, Schepense, Baeyens, \& Roeyers, 2009). These longitudinal results thus suggest that kindergarten and first grade children should be able to understand basic mathematical relational concepts, have number sequence and enumeration skills, and should be able to solve basic addition and subtraction tasks (verbal and symbolic), and that these skills form an important base for later math learning.

\subsection{Early mathematics learning in the Finnish context}

The structured teaching of mathematical skills to young children in Finnish early childhood education (i.e., children aged one to six years) is not a common nor desired practice, as in Finnish society, good early childhood education is centred on children's own activities and play, and it does not emphasise academic learning objectives (Ministry of Social Affairs and Health, 2002; Ojala \& Talts, 2007). Both Finnish parents and early childhood educators put less emphasis on pre-academic skills (Hujala-Huttunen, 1996). For kindergarten (i.e., instruction for six-year-olds, a year before the beginning of the first grade), the 
mathematics core curriculum given by the Finnish National Board of Education (here after FNBE) (2000) specifies the aims on a very general level. The aim is for children to have meaningful mathematical experiences of math concepts, such as classification, seriation, comparison and quantities, mainly by means of play, games, stories, songs, physical exercise and discussions along with representational material. Most often in teaching material (e.g., Takala \& Tienhaara, 2009) the instruction concentrates on mathematical relational concepts such as comparison (e.g., as many as, more, less, the same number), classification, and number word sequence and enumeration skills with numbers $0-5$ during the autumn term of the kindergarten year. During the spring term, the children practise mathematical relational skills (i.e., comparison, classification), number word sequence and enumeration skills with numbers from 6 to 10. The participation in kindergarten education in Finland is voluntary, but almost full enrolment is recorded nationwide (FNBE, 2010).

The core curriculum for mathematics (FNBE, 2004) for grades one and two, includes numbers and calculations (incl. number symbols, properties of numbers: comparison, classification, ordering, using concrete means to partition numbers; addition and subtraction using natural numbers), algebra, geometry and measurement. Mathematics textbooks comprise the basic teaching material. At first grade, it (e.g., Haapaniemi, Mörsky, Tikkanen, Vehmas, \&Voima, 2006a, 2006b) concentrates on number word sequence skills, enumeration skills, comparison and seriation skills with numbers 0- 12 during the autumn term. Also, addition and subtraction skills within the same number range are practised including some verbal problem solving tasks. During the spring term, children concentrate on practising the addition and subtraction skills mainly with numbers between 0 and 20, learning basic geometry and measurement, and are introduced to numbers up to 100 at the end of the school year. Children in the first grade generally have three mathematics lessons per week, of 45 minutes each.

\subsection{Age, gender, and early mathematics}

Age is a well-known factor contributing to children's mathematical competence (J ordan, Kaplan, Oláh, \& Locuniak, 2006; Ransdell \& Hecht, 2003). Very young children's mathematical competence is basic by nature, but as children grow up they learn more complex mathematical skills. Age is also an educationally relevant factor since the variation in children's chronological age in one kindergarten or first grade classroom can be up to 12 months, and even more in terms of the actual mathematical skill level (Boardman, 2006; Dowker, 2008; Hojnoski, Silberglitt, \& Floyd, 2009). Several studies suggest that girls and boys possess identical primary numerical abilities (Dehaene, 1997). However, in specific age cohorts results are contradictory: research focusing on the British National Curriculum Key Stage 1 measurements (with children aged four to seven years) report gender differences favouring girls in basic arithmetic tasks (Demie, 2001; Gorard, Rees, \& 
Salisbury, 2001; Strand, 1997, 1999). More precisely, a study by Strand (1999) showed that girls performed better than boys at the age of four years (Baseline measurement) and at the age of seven (Key Stage 1 measurement), but that the progress of boys was greater than that of girls between the two measurement points. Similarly, compared to same aged boys, better early numeracy skills have been found in Finnish girls aged four to seven years (Aunio, Hautamäki, Heiskari, \& Van Luit, 2006) and in Australian girls aged five to six years (Boardman, 2006). In contrast, Jordan and her colleagues (2006) found that kindergarten boys outperformed girls in the overall number sense, nonverbal calculation and estimation skills. Yet, in the early grades, no universal gender differences have been found in mathematical performance (Aunola et al., 2004; Carr \& J essup, 1997). Current findings on gender differences in children's mathematical performance are thus rather mixed and potentially confounded with skill- and age-related differences.

\subsection{Present study}

We were interested in finding out how the performance of children in mathematical skills varied at the beginning of the kindergarten and first grade year, if gender or age would affect the performance, and which mathematical skills were especially difficult for lowperforming children.

\section{Method}

\subsection{Participants}

We used two samples, which were collected as part of our nationwide research project Think Science and Math' (funded by the Finnish Ministry of Education and Culture, 201114).

Volunteering kindergarten teachers from one northern town of Finland were recruited to assess the early mathematics performance of their teaching group. The town was a smallsized town with slightly more than 13,000 inhabitants, the percentage of adults with at least lower secondary education was 73\% (average in Finland 67\%) and the unemployment rate was $11 \%$ (average in Finland 10\%) (Statistics Finland, 2011). All children were attending a public kindergarten education. The children had started the kindergarten in mid-August. A total of 177 children were present in the testing session in November $\left(\mathrm{M}_{\mathrm{age}}=76.4\right.$ months, $\mathrm{SD}=3.7$ months; 95 boys, 82 girls). All children had written permission authorized by their parents to participate in the study.

Volunteering first grade teachers from one southern town of Finland were recruited to assess the mathematics performance of their teaching group. The town was a medium-sized town with slightly more than 20,000 inhabitants, the number of adults with at least lower secondary education was $72 \%$ (average in Finland 67\%) and the unemployment rate was 9\% 
(average in Finland 10\%) (Statistics Finland, 2011). All children were attending a first grade class in public schools. A total of 178 children were present in the testing session in September ( $\mathrm{M}_{\mathrm{age}}=87.2$ months, $\mathrm{SD}=3.7$ months; 85 boys and 93 girls). The testing was done as a part of teachers' own professional training development activities, the researchers received children's answer sheets without any identification information.

\subsection{Measures}

Both kindergarten and first grade measures were developed based on the research literature concerning early mathematical development (e.g., Sarama \& Clements, 2009), and piloted before applying in this study.

The Screening Early Numeracy Skills (SENS) (Mononen \& Koponen, 2010) is a two-sheet paper-pencil test to be administered in a group of 8-10 kindergarteners, and takes about 15- 20 minutes to accomplish. The test includes eight tasks measuring mathematical relational concepts, such as relational words in comparisons with quantities (e.g., more, as many as) and seriation (e.g., ordinality), six tasks measuring enumeration skills (quantitynumber word-symbol relations), and four tasks measuring early addition and subtraction skills as verbal problem solving tasks (see examples of tasks in Appendix, Table A1). The number range used in most of the items is from 1 to 10 . In each task, a verbal instruction is given and can be repeated, if necessary. Answering requires only drawing X-marks on top of the pictures, or drawing circles or tallies into empty boxes. One point is given for every correct answer and zero for a false response, with a maximum composite score of 18 points. The reliability, in terms of Cronbach's coefficient alphas, of all of the children's scores on the measurement was acceptable (Table 1), except for early addition and subtraction skills, which only nearly reached the acceptable level. These items were, however, kept in the analysis, as all of the items correlated significantly $(\mathrm{p}<.01)$ with the total composite score.

Table 1 Descriptive statistics of the kindergarten measure Screening Early Numeracy Skills.

\begin{tabular}{llll}
\hline Scale & \multicolumn{3}{c}{$(\mathrm{N}=177)$} \\
\cline { 2 - 4 } & $\mathrm{M}$ & $(\mathrm{SD})$ & $\alpha[95 \% \mathrm{CI}]$ \\
\hline Relational concepts $(\max 8)$ & 6.86 & $(1.29)$ & $.62[.52-.70]$ \\
Enumeration $(\max 6)$ & 5.29 & $(1.16)$ & $.67[.58-.74]$ \\
Early addition and subtraction $(\max 4)$ & 2.71 & $(1.17)$ & $.56[.44-.65]$ \\
Whole scale (max 18) & 14.88 & $(2.81)$ & $.77[.72-.82]$ \\
\hline
\end{tabular}

Note. $\alpha[95 \% \mathrm{CI}]=$ Cronbach's coefficient alpha with confidence intervals. 
First Grade Numeracy Skills Assessment (FGNSA) (Aunio \& Mononen, 2011) is a fivesheet paper-pencil test to be administered in a group of children in classrooms, and takes 30- 45 minutes to accomplish. The emphasis in the first grade on numbers and calculations is in the number range from 1 to 20. The tasks in FGNSA also include numbers up to 100, which are taught at the end of the first grade. Relational tasks (four items) measure the knowledge of magnitude comparison (e.g., more, less). Number sequence tasks include items measuring ordinal numbers and number sequences forward and backward (29 items). Enumeration tasks tap into the children's understanding of the quantity-number word-symbol relations (14 items). Addition and subtraction fluency was investigated with the number range of 1-20. There are 40 addition and 40 subtraction items, for each scale the child has two minutes to complete as many facts as possible (see examples of items in Appendix, Table A2). A test administrator gives verbal task instruction to the children and can repeat it once if needed. After finishing the task, a child will wait until a test administrator presents the next task. Answering requires drawing X-marks on top of the pictures or drawing number symbols. One point is given for every correct answer and zero for a false response, with a maximum composite score of 47 points. Addition and subtraction tasks were not included in this composite score, but analysed separately having 40 points total score each. We excluded four items measuring relational skills as they did not correlate significantly with the composite score, causing reliability problems. The new composite score without these items was then 43 points. The reliability, in terms of Cronbach's coefficient alphas, of all of the children's scores on the measurement was acceptable (Table 2).

Table 2 Descriptive statistics of the first grade measure First Grade Numeracy Skills Assessment.

\begin{tabular}{lccc}
\hline \multirow{2}{*}{ Scale } & \multicolumn{3}{c}{$(\mathrm{N}=178)$} \\
\cline { 2 - 4 } & $\mathrm{M}$ & $(\mathrm{SD})$ & $\alpha[95 \% \mathrm{CI}]$ \\
\hline Number word sequences $(\max 29)$ & 19.76 & $(5.74)$ & $.89[.87-.91]$ \\
Enumeration $(\max 14)$ & 11.03 & $(3.22)$ & $.85[.82-.88]$ \\
Whole scale $(\max 43)$ & 30.79 & $(8.42)$ & $.93[.91-.94]$ \\
2 min Addition $(\max 40)$ & 13.14 & $(5.45)$ & $.91[.89-.93]$ \\
2 min Subtraction $(\max 40)$ & 11.43 & $(5.13)$ & $.90[.88-.92]$ \\
\hline
\end{tabular}

Note. $\alpha[95 \% \mathrm{CI}]=$ Cronbach's coefficient alpha with confidence intervals.

\subsection{Procedure}

The teachers in both samples were supplied with test materials. The testing manuals included precise instructions on how to implement the tests. All teachers were familiar with conducting testing sessions similar to those applied in this study. The teachers were advised to contact the authors if they had any questions concerning the measures or the 
measurement procedures. The kindergarten teachers conducted assessment in groups of 810 children. The assessment took approximately 15- 20 minutes to accomplish. The first grade teachers conducted assessment in the classrooms of 17- 22 children. The assessment took around 30-45 minutes. After the assessment session, the teachers sent the answer sheets to the authors, who scored the children's answers and keyed in the data.

\subsection{Data analysis}

Preliminary analysis revealed that both the kindergarten and first grade scales were negatively skewed, and not normally distributed. To be able to use parametric tests, we used square root transformation for the data (Tabachnick \& Fidell, 1996). For the sake of a better interpretation of the results, the means and standard deviations are reported as original means and standard deviations. The other statistical values of the tests (e.g., F- and p-values) reported are calculated from transformed variables used in the analyses.

The data, for both kindergarten and first grade, was analysed in two stages: firstly, we examined age and gender differences, by comparing transformed composite scores using ANOVA. Secondly, four performance groups within each sample were formed based on the original composite score, in order to compare especially low-performing children's performance with the performance of the other groups. Comparisons in composite and subtask scores between the performance groups were analysed using ANOVA with Bonferroni-adjustment in order to decrease the Type I error. If the ANOVA test produced a significant main effect, we continued with Bonferroni-adjusted post-hoc tests. Results were also examined in an item level, in order to identify the most difficult items for lowperforming children.

\section{Results}

\subsection{Kindergarten}

In the kindergarten data there was a significant age effect, $F(13,163)=2.72, p=.002$, with younger children having lower mean scores than the older children. There was no significant difference found for gender (boys $\mathrm{M}=14.55$, $\mathrm{SD}=2.91$; girls $\mathrm{M}=15.26$, $\mathrm{SD}=$ 2.65), $\mathrm{F}(1,175)=3.18, \mathrm{p}=.076$

We created a performance level variable using the original total composite score of SENS with benchmarks of 25th, 50th and 75th percentiles. Children scoring at or below the 25th percentile, scoring 0- 13 points, formed the low-performing group (LOW, $\mathrm{n}=44$ ), children scoring 14-15 points formed the medium-performing group (MED, $n=53$ ), children scoring 16-17 points formed the high-performing group ( $\mathrm{HIGH}, \mathrm{n}=43$ ), and children scoring in the top 25th percentile, that is 18 points, formed the top-performing 
group (TOP, $\mathrm{n}=37$ ). So, $20.9 \%$ of children had already mastered all of the skills measured. An ANOVA test supported the group formations, showing that there was a significant difference between the performance groups on the whole scale as well as in different skills. The performance of the LOW group compared to the other three groups was significantly weaker (see Table 3). Although previous analysis suggested that younger children perform weaker than older children, such age differences did not exist between the four groups, $F(3,173)=1.06, p=.369$. The results of the supplementary analysis showed that most of the younger children were found in two groups, LOW and MED, meaning that the youngest children were not always those having the lowest scores.

Considering results at an item level, the low-performing children showed weakness across the items when the numbers used in an item exceeded six. The most difficult items were the ones measuring basic addition and subtraction skills. The easiest ones for these children were items measuring understanding of comparison words (e.g., as many as, more, less, least) with small quantities.

\subsection{First grade}

In the first grade data a significant age difference was found, $F(14,163)=1.78, p=.045$, with younger children having lower mean scores than the older ones. There was no statistically significant difference found for gender (boys $\mathrm{M}=31.08, \mathrm{SD}=8.72$; girls $\mathrm{M}=$ 30.53, $\mathrm{SD}=8.17), \mathrm{F}(1,176)=0.43, \mathrm{p}=.598$.

Performance groups were formed in a similar manner as with kindergarten data. Children scoring at or below the 25th percentile, that is $0-25$ points, formed the lowperforming group (LOW, $\mathrm{n}=47$ ), children scoring 26- 32 points formed the mediumperforming group (MED, $\mathrm{n}=42$ ), children scoring 33-37 points formed the highperforming group ( $\mathrm{HIGH}, \mathrm{n}=45$ ), and children scoring in the top 25th percentile, that is 38-43 points, formed the top-performing group (TOP, $n=44$ ). An ANOVA test supported the group formations, showing that there was a significant difference between the performance groups on the whole scale as well as in different skills. The performance of the LOW group in comparison to the other three groups was significantly weaker in all skill areas (see Table 4). A statistically significant difference between the groups was found for age, $F(3,174)=2.69, p=.048$. However, based on post-hoc comparisons, of all groups only the LOW and TOP groups nearly showed a significant difference in age, $p=.055$, the lowperforming children being younger.

Considering results at a task level, the low-performing children showed weakness in both forward and backward number sequences by one's as the numbers used exceeded 10. Skip counting forward and backwards by two's or five's were the most difficult items in the whole test for the LOW children. In enumeration tasks, the amount of correct responses dropped as the items included numbers bigger than 10. In addition and subtraction task 


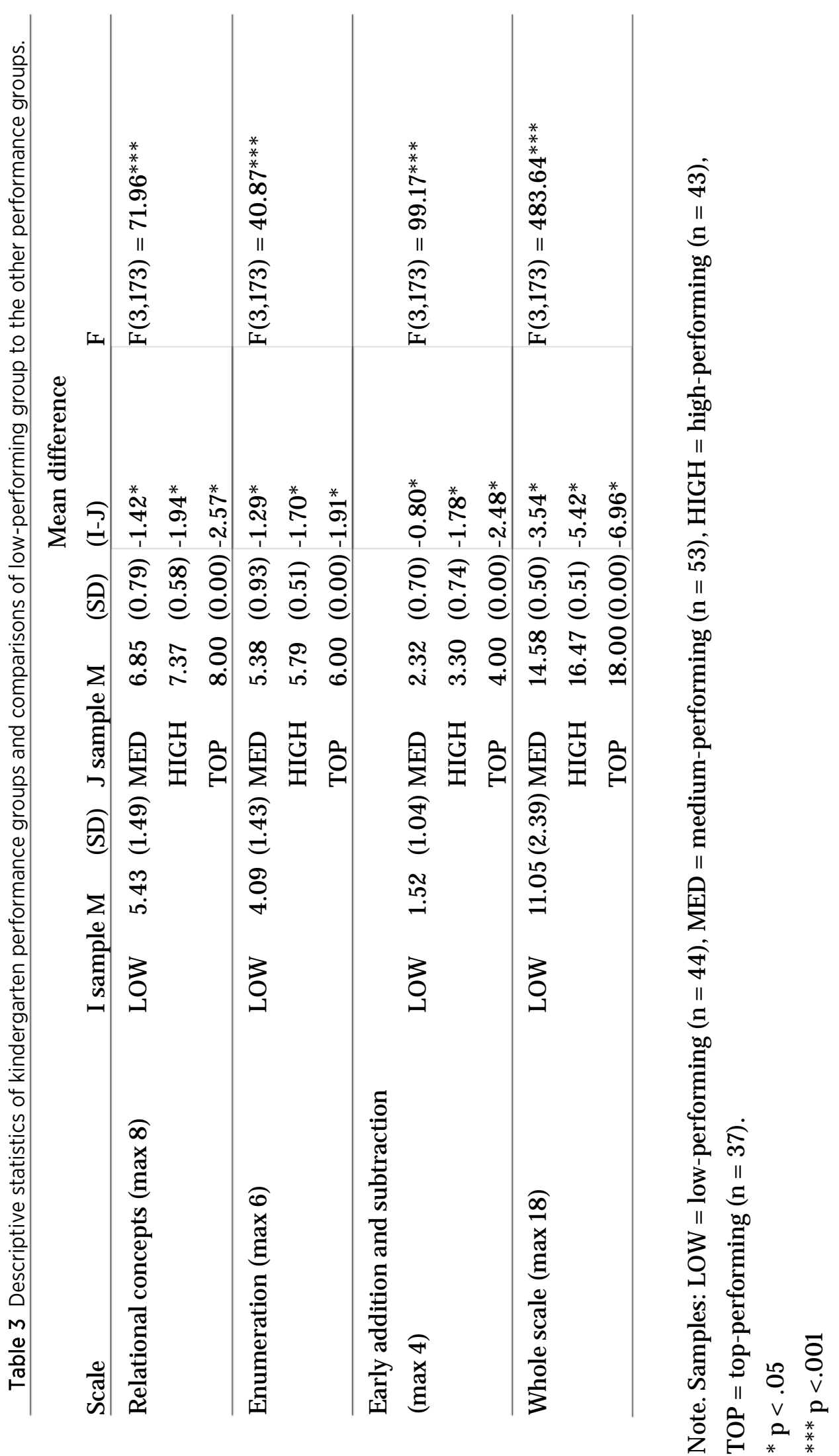




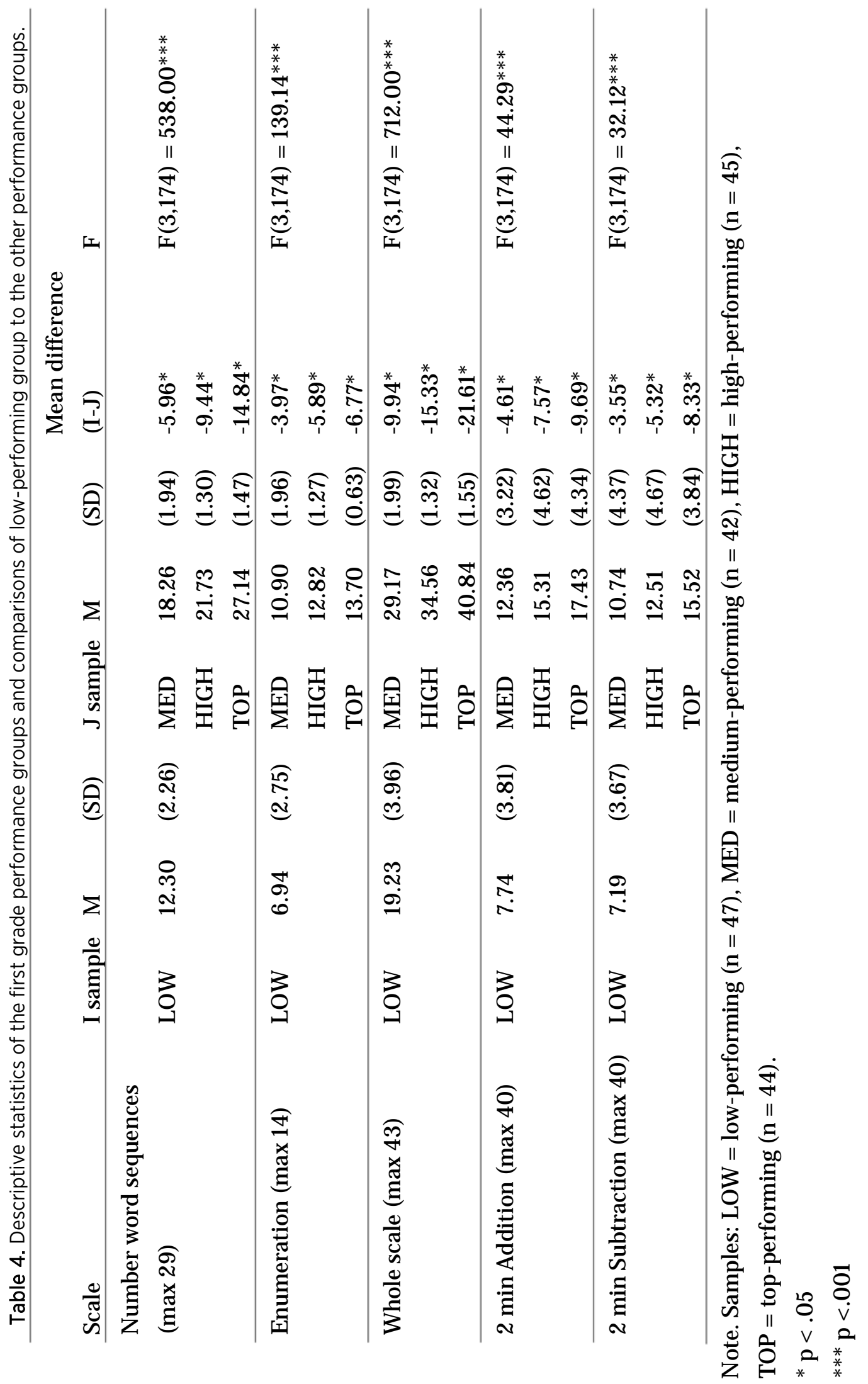


the LOW children calculated accurately, as the correctness in each item was around $80 \%$ or more, however the LOW children were slower than their peers. On average, the LOW children calculated nearly half the number of items in two minutes compared to their peers.

\section{Discussion}

The purpose of the present study was to investigate how the performance of children in mathematical skills varied at the beginning of the school year, if gender or age would affect the performance, and which mathematical skills were especially difficult for low-performing children. In both kindergarten and first grade, there was no gender difference found between the children in early mathematics, in contrast with previous results (Aunio et al., 2006; Boardman, 2006; J ordan et al., 2006), but in support of the fact that there seems to be no constant gender difference in early math performance. We found the similar age effects in kindergarten and first grade, namely the younger kindergarten children and first graders had weaker performance than their peers, replicating the results from other European countries some time ago (Kavkler, Aubrey, Tancig, \& Magajna, 2000; Sharp, Hutchinson, \& Whetton, 1994). It is plausible to suggest that older children have had more opportunities to practise and get acquainted with mathematical issues, and maybe they are also more prepared to complete our assessment tools, which required concentration and listening skills, as the teacher gave the instructions verbally during the assessment session.

Our results demonstrate that performance differences in mathematical skills were already present before the onset of formal schooling (Aunio et al., 2009; Jordan et al., 2009) and in the first grade. Children performing in the lowest 25th percentile in both samples were weaker in all sets of items measuring different mathematical skills compared to the other three higher performance groups. Consistent with earlier research (e.g., Clarke, Clarke, \& Cheeseman, 2006), we found that many children already understood much of what is considered in mathematics curriculum and materials in their forthcoming school year in the kindergarten or the first grade.

Low-performing children have challenges with most of the mathematical skills measured. In general, Finnish kindergarten mathematics core curriculum and materials put emphasis on learning relational skills in a numerical context, that is, comparison, classification and seriation. Our results show that even low-performing children are familiar with these relational concepts when they begin their kindergarten year. On the other hand, number sequence and enumeration skills were the areas where low-performing children showed weaker skills. Therefore, it seems plausible to suggest that extra learning support should be aimed, for example, at counting skills, which lay the foundation for further learning of mathematics and are considered as a good predictor for later learning (Aubrey et al., 2006; Krajewski \& Schneider, 2009). The weak children would need the time 
and opportunities to practise all of their mathematical skills, in order to be able to catch up to their average performing peers (Gersten et al., 2009).

At the beginning of the first grade, the low-performing children had problems in very basic early mathematical skills. As number sequence, counting, and basic arithmetical skills are essential for further meaningful learning (Aunola et al., 2004; J ordan et al., 2007), the progress of children performing poorly in these skills at the beginning of the school year should, therefore, be constantly monitored with care and the required support provided. It seems that the first grade teaching material provides enough practice opportunities for lowperforming children in number sequence, enumeration, and basic addition and subtraction skills with the number range $0-20$. Thus, the children benefiting most from the curriculum content would be the low performers. This raises a question, what then should be taught to those children who have already mastered many skills, in order not to widen the gap even more between the low and typically performing children. Intervention studies provide evidence that there are efficient ways to support children's diverse learning, both long-term interventions including several mathematical skills (Chard et al., 2008) and short-term interventions focusing on one or two mathematical skills (Ramani \& Siegler, 2011; Sood \& Jitendra, 2011) seem to be effective. Hence, the evidence-based enrichment materials providing meaningful learning opportunities also for those children performing above average is needed.

The limitations of this study should be addressed in future research. Using longitudinal design with several follow-up measurement points would give us information about whether screening at the beginning of kindergarten or grade one is reliable enough to find children at-risk for mathematics difficulties, or if additional assessment points are needed to identify all potential at-risk children (Morgan et al., 2009). Follow-up measurements would also inform how initially low-performing children benefit from general educational support; is their performance stable throughout the school year, or does their performance change during the year, from one performance group to another.

There is an interesting paradox with core curriculum provided by the FNBE (2004), teaching materials provided by publishing houses, and what the children master and spend their time with. Core curriculum is quite superficial by nature, giving a lot of freedom to teachers and teaching material publishers, ending up with the fact that the high-performing children currently practise the exact skills that they have already mastered for at least the first half year. We are not suggesting that we should have higher learning goals for all children, as our study shows that the weak children would benefit from the current curriculum content. It might be wise, though, to consider together with educators, school administrators and educational researchers, what the minimum topics should be that would be relevant to be learnt at the beginning of the school career, to be able to understand mathematics instruction later on. Current longitudinal studies suggest that these include good number word sequence skills, enumeration skills and basic arithmetical 
skills, supported by an understanding of relational skills (Aubrey et al., 2006; J ordan et al., 2007; Krajewski \& Schneider, 2009). In addition, non-verbal number sense seems to form relevant supporting skills for mathematical development (LeFevre et al., 2006, Wilson et al., 2006). It is also important to think, what are the possibilities to expand the minimum goals, as also the high-performing children should be provided with opportunities to elaborate on their mathematical knowledge. We suggest that enrichment instruction materials should be designed, so that it is possible to give good opportunities for learners from all performance levels.

\section{References}

Aubrey, C., Dahl, S., \& Godfrey, R. (2006). Early mathematics development and later achievement: Further evidence. Mathematics Education Research J ournal, 18(1), 27- 46.

Aunio, P., Hautamäki, J ., Heiskari, P., \&Van Luit, J . E. H. (2006). The Early Numeracy Test in Finnish: Children's Norms. Scandinavian J ournal of Psychology, 47, 369- 378.

Aunio, P., Hautamäki, J., Sajaniemi, N., \&Van Luit, J . E. H. (2009). Early numeracy in lowperforming young children. British Educational Research J ournal, 35(1), 25- 46.

Aunio, P., Hautamäki, J ., \& Van Luit, J . E. H. (2005). Mathematical thinking intervention programmes for preschool children with normal and low number sense. European J ournal of Special Needs Education, 22(2), 131- 146.

Aunio, P. \& Mononen, R. (2011). First Grade Numeracy Skills Assessment (FGNSA). Unpublished.

Aunio, P. \& Niemivirta, M. (2010). Predicting children's mathematical performance in grade one by early numeracy. Learning and Individual Differences, 20(5), 427- 435.

Aunola, K., Leskinen, E., Lerkkanen, M.-K, \& Nurmi, J .-E. (2004). Developmental dynamics of math performance from preschool to Grade 2. J ournal of Educational Psychology, 96, 699- 713.

Aunola, K., Leskinen, E., \& Nurmi, J .-E. (2006). Developmental dynamics between mathematical performance, task motivation, and teachers' goals during the transition to primary school. British J ournal of Educational Psychology, 76, 21- 40.

Boardman, M. (2006). The impact of age and gender on prep children's academic achievements. Australian J ournal of Early Childhood, 31(4), 1-6.

Bryant, D. P., Bryant, B. R., Gersten, R. M., Scammacca, N. N., Funk, C., Winter, A., ...Pool, C. (2008). The effects of tier 2 intervention on the mathematics performance of first-grade students who are at risk for mathematics difficulties. Learning Disability Quarterly, 31, 47-63.

Bryant, D. P., Bryant, B. R., Roberts, G., Vaughn, S., Hughes Pfannenstiel, K., Porterfield, J ., \& Gersten, R. (2011). Early numeracy intervention program for first-grade students with mathematics difficulties. Exceptional Children, 78(1), 7- 23.

Carr, M. \&J essup, D. (1997). Gender differences in first grade mathematics strategy use: Social and metacognitive influences. J ournal of Educational Psychology, 89, 318- 328.

Chard, D. J ., Baker, S. K., Clarke, B., J ungjohann, K., Davis, K., \& Smolkowski, K. (2008). Preventing early mathematics difficulties: The feasibility of a rigorous kindergarten mathematics curriculum. Learning Disability Quarterly, 31, 11- 20.

Clarke, B., Clarke, D., \& Cheeseman, J . (2006). The mathematical knowledge and understanding young children bring to school. Mathematics Education Research J ournal, 18(1), 78- 102.

Dehaene, S. (1997). The number sense. How the mind creates mathematics. London, UK: Penguin Books. 
Demie, F. (2001). Ethnic and gender differences in educational achievement and implications for school improvement strategies. Educational Research, 43 (1), 91- 106.

Desoete, A., Stock, P., Schepense, A., Baeyens, D., \& Roeyers, H. (2009). Classification, seriation, and counting in grades 1,2 , and 3 as two-year longitudinal predictors for low achieving in numerical facility and arithmetical achievement? J ournal of Psychoeducational Assessment, 27(3), 252264.

Dowker, A. (2008). Individual differences in numerical abilities in preschoolers. Developmental Science, 11(5) 650-654.

Finnish National Board of Education. (2000). Core Curriculum for Pre-School Education 2000. http:// www.oph.fi/english/sources_of_information/core_curricula_and_qualification_require ments/pre-school_education

Finnish National Board of Education. (2004). National Core Curriculum for Basic Education 2004. http:// www.oph.fi/english/publications/2009/national_core_curricula_for_basic_education

Finnish National Board of Education. (2010). Quantitative Indicators of Education (9th ed.) Helsinki, Finland: National Board of Education.

Gersten, R., Beckmann, S., Clarke, B., Foegen, A., Marsh, L., Star, J . R., \&Witzel, B. (2009). Assisting students struggling with mathematics: Response to Intervention (RtI) for elementary and middle schools (NCEE 2009-4060). Washington, DC: National Center for Education Evaluation and Regional Assistance, Institute of Education Sciences, U.S. Department of Education. http:// ies. ed.gov/ ncee/ wwc/ publications/ practiceguides/

Gorard, S., Rees, G., \& Salisbury, J . (2001). Investigating the patterns of differential attainment of boys and girls at school. British Educational Research J ournal, 27(2), 125- 139.

Haapaniemi, S., Mörsky, S., Tikkanen, A., Vehmas, P., \& Voima, J . (2006a). Tuhattaituri 1a [Tuhattaituri 1a, mathematics textbook]. Helsinki: Otava.

Haapaniemi, S., Mörsky, S., Tikkanen, A., Vehmas, P., \& Voima, J . (2006b). Tuhattaituri 1b [Tuhattaituri 1b, mathematics textbook]. Helsinki: Otava.

Hojnoski, R. L., Silberglitt, B., \& Floyd, R. G. (2009). Sensitivity to grouth over time of the preschool numeracy indicators with a sample of preschoolers in Head Start. School Psychology Review, 38(3) 402-418.

Hujala-Huttunen, E. (1996). Day care in the USA, Russia and Finland: Views from parents, teachers and directors. European Early Childhood Education Research J ournal, 4(1), 33- 48.

J ordan, N. C., Glutting, J ., \& Ramineni, C. (2010). The importance of number sense to mathematics achievement in first and third grades. Learning and Individual Differences, 20, 82- 88.

J ordan, N. C., Kaplan, D., Oláh, L. N., \& Locuniak, M. N. (2006). Number sense growth in kindergarten: A longitudinal investigation of children at risk for mathematics difficulties. Child Development, 77(1) 153- 175.

J ordan, N. C., Kaplan, D., Ramineni, C., \& Locuniak, M. N. (2009). Early math matters: Kindergarten number competence and later mathematics outcomes. Developmental Psychology, 45(3), 850867.

J ordan, N. C., Kaplan, D., Locuniak, M. N., \& Ramineni, C. (2007). Predicting first-grade math achievement from developmental number sense trajectories. Learning Disabilities Research \& Practice, 22(1), 36- 46.

Kavkler, M., Aubrey, C., Tancig, S., \& Magajna, L. (2000). Getting it right from the start? The influence of early school entry on later achievements in mathematics. European Early Childhood Education Research J ournal, 8(1), 75- 93.

Klein, A., Starkey, P., Clements, D., Sarama, J ., \& Iyer, R. (2008). Effects of a pre-kindergarten mathematics intervention: A randomized experiment. J ournal of Research on Educational Effectiveness, 1, 155- 178.

Krajewski, K. \& Schneider, W. (2009). Early development of quantity to number-word linkage as a precursor of mathematical school achievement and mathematical difficulties: Findings from a four-year longitudinal study. Learning and Instruction, 19, 513- 526. 
Kurdek, L. A. \& Sinclair, R. J . (2001). Predicting reading and mathematics achievement in fourthgrade children from kindergarten readiness scores. J ournal of Educational Psychology, 93(3) 451- 455 .

Lachance, J . A. \& Mazzacco, M. M. M. (2006). A longitudinal analysis of sex differences in math and spatial skills in primary school age children. Learning and Individual Differences, 16, 195-216.

LeFevre, J .-A., Smith-Chant, B. L., Fast, L., Skwarchuk, S.-L., Sargala, E., Arnup, J . S., .... Kamawar, D. (2006). What counts as knowing? The development of conceptual and procedural knowledge of counting from kindergarten through Grade 2. J ournal of Experimental Child Psychology, 93, 285- 303.

Ministry of Social Affairs and Health. (2002). Decision in principle of the council of state concerning the national policy definition on early childhood education and care. Ministry of Social Affairs and Health, 2002:9. Helsinki, Finland.

Mononen, R. \& Koponen, T. (2010). Screening Early Numeracy Skills (SENS). Unpublished.

Morgan, P. L., Farkas, G., \&Wu, Q. (2009). Five-year growth trajectories of kindergarten children with learning difficulties in mathematics. J ournal of Learning Disabilities, 42, 306- 321.

Ojala, M. \& Talts, L. (2007). Preschool achievement in Finland and Estonia: Cross-cultural comparison between the cities of Helsinki and Tallinn. Scandinavian J ournal of Educational Research, 51(2), 205- 221.

Passolunghi, M. C., Vercelloni, B., \& Schadee, H. (2007). The precursors of mathematics learning: Working memory, phonological ability and numerical competence. Cognitive Development, 22(2), 165- 184.

Ramani, G. B. \& Siegler, R. S. (2011). Reducing the gap in numerical knowledge between low- and middle-income preschoolers. J ournal of Applied Developmental Psychology, 32, 146- 159.

Ransdell, S. \& Hecht, S. (2003). Time and resource limits on working memory: Cross-age consistency in counting span performance. J ournal of Experimental Child Psychology, 86, 303- 313.

Räsänen, P., Salminen, J., Wilson, A. J ., Aunio, P., \& Dehaene, S. (2009). Computer-assisted intervention for children with low numeracy skills. Cognitive Development, 24, 450-472.

Sarama, J . \& Clements, D. H. (2009). Early childhood mathematics education research. Learning trajectories for young children. New York, NY: Routledge.

Sharp, C., Hutchinson, D., \&Whetton, C. (1994). How do season of birth and length of schooling affect children's attainment at key stage 1? Educational Research, 36(2), 107- 121.

Sood, S. \&J itendra, A. K. (2011). An exploratory study of a number sense program to develop kindergarten students' number proficiency. J ournal of Learning Disabilities, 1- 19.

Statistics Finland. (2011). Regional and geographic information services. http://tilastokeskus.fi/tup/ kunnat/

Strand, S. (1997). Pupil progress during Key Stage 1: a value-added analysis of school effects. British Educational Research J ournal, 23(4), 471- 487.

Strand, S. (1999). Ethnic group, sex, and economic disadvantage: associations with pupils educational progress from Baseline to the end of Key Stage 1. British Educational Research J ournal, 25(2), 179- 202.

Tabachnick, B. G. \& Fidell, L. S. (1996). Using multivariate statistics. (Third Edition). New York, NY: Harper Collins.

Takala, O. \&Tienhaara, M. (2009). Eskarin Matikka [Kindergarten Math]. Helsinki: WSOY.

Wilson, A. J., Dehaene, S., Pinel, P., Revkin, S. K., Cohen, L., \& Cohen, D. (2006). Principles underlying the design of "The Number Race", an adaptive computer game for remediation of dyscalculia. Behavioral and Brain Function, 2(1), 20. 


\section{Appendix}

Table 1A Task examples of the Screening Early Numeracy Skills (SENS) measure.

\begin{tabular}{|c|c|}
\hline Task & Item \\
\hline $\begin{array}{l}\text { Relational } \\
\text { concepts }\end{array}$ & $\begin{array}{l}\text { "There are balls ( } 4 \text { ) in the picture. Mark the box with as many stars as } \\
\text { balls." ( } 3 \text { choices) }\end{array}$ \\
\hline $\begin{array}{l}\text { Relational } \\
\text { concepts }\end{array}$ & "Mark the seventh ball." (18 balls in line) \\
\hline $\begin{array}{l}\text { Relational } \\
\text { concepts }\end{array}$ & $\begin{array}{l}\text { "There are cars ( } 5 \text { ) in the picture. Mark the box with more balls than } \\
\text { cars." ( } 3 \text { choices) }\end{array}$ \\
\hline Enumeration & “Mark six stars.” (from 8 stars) \\
\hline Enumeration & $\begin{array}{l}\text { "There is a number (8) in the box. Draw as many balls as the number } \\
\text { shows." }\end{array}$ \\
\hline Enumeration & $\begin{array}{l}\text { "There are some balls (6) in the box. Mark the number, which shows } \\
\text { how many balls there are." (from } 5,6,7,8 \text { ) }\end{array}$ \\
\hline $\begin{array}{l}\text { Early addition } \\
\text { and subtraction }\end{array}$ & $\begin{array}{l}\text { "Mike has four marbles (shown in the picture). Peter has two marbles } \\
\text { more than Mike. How many marbles does Peter have?" (the child } \\
\text { draws the correct amount of marbles.) }\end{array}$ \\
\hline $\begin{array}{l}\text { Early addition } \\
\text { and subtraction }\end{array}$ & $\begin{array}{l}\text { "You have five stickers (shown in the picture). You give three stickers } \\
\text { to your friend. How many stickers do you have then?" (the child } \\
\text { marks the correct picture of quantity, } 3 \text { choices.) }\end{array}$ \\
\hline
\end{tabular}


Table 2A Task examples of the First Grade Numeracy Skills Assessment (FGNSA) measure.

\begin{tabular}{|c|c|}
\hline Task & Item \\
\hline $\begin{array}{l}\text { Number } \\
\text { sequences }\end{array}$ & $\begin{array}{l}\text { Look at the forward number sequence. One number is missing. Write } \\
\text { down the missing number. e.g., } 1,2,{ }_{--}, 4\end{array}$ \\
\hline $\begin{array}{l}\text { Number } \\
\text { sequences }\end{array}$ & $\begin{array}{l}\text { Look at the backward number sequence. One number is missing. } \\
\text { Write down the missing number. e.g., } 16,15, \ldots, 13\end{array}$ \\
\hline $\begin{array}{l}\text { Number } \\
\text { sequences }\end{array}$ & What number comes next? e.g., 24, \\
\hline $\begin{array}{l}\text { Number } \\
\text { sequences }\end{array}$ & What number comes just before? e.g., _-, 18 \\
\hline Enumeration & $\begin{array}{l}\text { Write down the number you hear. e.g., "fifteen" (number word - } \\
\text { symbol) }\end{array}$ \\
\hline Enumeration & $\begin{array}{l}\text { Count the number of dots and write it down. e.g., nine dots (quantity - } \\
\text { symbol) }\end{array}$ \\
\hline Enumeration & $\begin{array}{l}\text { Look at the number next to the box with empty dots. Colour as many } \\
\text { dots as the number tells. e.g., } 11 \text { (symbol - quantity) }\end{array}$ \\
\hline Addition & $\begin{array}{l}40 \text { addition facts (number range 1-20) in horizontal form, e.g., } 4+2 \\
=\text {. A two-minute time limit. }\end{array}$ \\
\hline Subtraction & $\begin{array}{l}40 \text { subtraction facts (number range 1- 20) in horizontal form, e.g., } 6 \text { - } \\
4=. \text { A two-minute time limit. }\end{array}$ \\
\hline
\end{tabular}


